nistro de calor y succión continua de las mucosidades. La coramina se repetirá cada 4 a 8 horas, $1 / 4$ a $1 / 2$ centímetro cúbico por vía subcutánea o intramuscular, o sustituírse por las gotas por vía oral, 5 gotas cada 2 o 4 horas. También se puede administrar la adrenalina en dosis de 2 a 4 gotas 3 o 4 veces al día.

Profilaxis. Está en manos del obstetra.
Bibliografia.

Stone. The New born Infant.

Arce. Patología del recién nacido.

Holt y McIntosh. Tratado de Pediatría.

Litchfield and Dembo. Therapeutics of Infancy and Childhood.

Bernal L. Francisco. Oxígeno intragástrico (tesis).

\title{
HISTERECTOMIA ESPONTANEA
}

\author{
Doctor CARLOS R. SILVA MOJICA \\ Jefe de Clinica Obstétrica
}

Con esta denominación presento un caso interesante dentro de la Clínica Obstétrica y Ginecológica. La historia expuesta en seguida, nos pone de presente la evolución especial que siguió una matriz fibromatosa durante el puerperio de un aborto de 6 meses. El fibroma fue atacado de necrobiosis, y tras de muchos incidentes infecciosos y tóxicos de carácter grave se llegó al acto quirúrgico. Se encontró la matriz necrosada, libre dentro de una cavidad de membranas de neoformación. El proceso séptico había llevado a cabo una amputación de la matriz sobre el itsmo. La labor quirúrgica se redujo a practicar una simple laparotomía nada más, porque la matriz ya estaba libre. Con el concurso de la acción infecciosa como también de las defensas propias de la paciente se habia efectuado ya una histerec- tomía, que por sus características me parece apropiado calificar de espontánea.

Hé aquí los hechos: "Instituto de Protección Materno e Infantil. Servicio del Profesor Mojica. Historia número 670. Fecha de inscripción: abril 22 de 1949. Nombre: L. de G., de 33 años, casada, natural de Guachetá; ocupación: oficios domésticos. Diagnóstico de ingreso: Amenaza de aborto. Diagnóstico definitivo: primipara de 6 meses aborto incompleto en el hospital. Extracción de restos ovulares y taponamiento. Fibroma uterino. Necrobiosis. Histerectomía espontánea.

Antecedentes familiares y hereditarios: sin importancia. Personales: viruela; enfermedades de la infancia. Ginecológicos: menarquia a los 12 años, ciclo: $28 \times 4$; menstruaciones dolorosas; cantidad abundante. 


\section{Embarazo actual.}

La última menstruación terminó el 18 de octubre de 1948 . Ha padecido de náuseas y acedías. Acude al hospital porque además de estos síntomas ha tenido otros malestares: mareos, cefaleas, dolor persistente en el bajo vientre. En el mes de enero hubo hemorragia genital escasa sero-sanguinolenta, acompañada de dicho dolor, que persistió por algunos días. Al ingresar al Servicio no se aprecia ya hemorragia pero el dolor se mantiene constante.

Examen general: temperatura, 36,8 ; pulso, 90. T. A. $12 \frac{1}{2}$ de max. por $7 \frac{1}{2}$ de min. Diferencial: 5. Aparatos respiratorio, circulatorio, digestivo y urinario: normales.

Examen obstétrico: pared abdominal de tonicidad normal. Altura uterina: 23 centímetros. Cualidades del útero: Llama la atención su consistencia dura; forma globulosa superficie regular; dirección mediana; tonicidad alta.

Por estas condiciones de la matriz no es posible apreciar polos ni partes fetales ni la cantidad de líquido amniótico. Igualmente la auscultación fetal es negativa. Pelvimetría externa: normal. Tipo de bacinete: ginecoide. T. V.: (Abril 23 a las 12 $-(-20)$. Vulva y vagina normales. Cuello parcialmente borrado, grueso, blando; la dilatación apenas da paso a un dedo y es posible tocar un polo fetal a través de las membranas, que por sus características da la impresión de una pelvis.

En resumen, los sintomas más importantes eran: amenorrea de $6 \mathrm{me}-$ ses; desacuerdo entre la fecha de U. R. (18 de octubre de 1948) y la A.
U. (23 centímetros), en favor de ésta con 3 centímetros. Dolor persistente, cantinuo en el bajo vientre desde hacía $3 \frac{1 / 2}{2}$ meses. Dato de una hemorragia genital escasa hacía 3 meses. Consistencia dura de la matriz. Dolor espontáneo y provocado de este órgano. Ausencia de ruidos y de movimientos fetales. Imposibilidad de baloteo fetal por la rigidez y por la sensibilidad uterinas.

Sin llegar a ningún diagnóstico de certeza por el momento, se ordenan exámenes de laboratorio (Friedmann, orina, cuadro hemático), se sigue una conducta médica de expectativa a base de progesterona y de sedantes y ante la diversidad de los sintomas se tienen en cuenta las siguientes entidades: a) Amenaza de aborto; b) Desprendimiento prematuro de la placenta normalmente insertada; c) Muerte y retención del feto; d) Coexistencia de embarazo y quiste del ovario con pedículo torcido y doloroso; e) Hemetometría.

Pero tres días después del 25 de abril de 1949 ocurre el aborto de un feto muerto masculino de 500 gramos, con retención de placenta y membranas y hemorragia persistente que obliga al Interno a tomar medidas activas. T. V.: cuello abierto, borrado, desviado hacia la izquierda, rechazado por una masa o fibroma grande de la mitad derecha de matriz y que deja libre el cuerno izquierdo y una pequeña cavidad uterina colocada hacia la izquierda. El Interno pudo apreciar en ese momento un fibroma bastante grande, pues le anotó una altura de 18 centímetros aproximadamente. Como encontrara restos ovulares, procede a hacer la extracción con pinzas de 
falsos gérmenes y como continuara una hemorragia pequeña, practica un taponamiento con mecha saturada de sulfa.

Con el hallazgo del fibroma durante el aborto se encuentra explicación satisfactoria a todos los síntomas concomitantes con el estado grávido.

En los dos primeros días del puerperio el tumor aunque sensible, disminuyó un poco de altura, pero del tercer día en adelante se hizo aún más doloroso, aumentó de tamaño hasta 22 centímetros de altura y se hizo más notoria su consistencia dura y leñosa; al mismo tiempo la temperatura ascendió a $39^{\circ}$ y $40^{\circ}$ con aceleración del pulso (120 y 130 al minuto) y el estado general se afectó visiblemente. Los loquios se tornaron abundantes y muy fétidos de olor francamente gangrenoso. Practiqué un T. V.; pude comprobar un gran fibroma localizado en el fondo y toda la cara anterior de la matriz, hasta el itsmo. La cavidad uterina se apreciaba muy estrecha, limitada atrás por una pared delgada formada por matriz sana, mientras que por los lados y por delante la pared era bastante gruesa, pues correspondía al fibroma.

Se sospecha una necrobiosis séptica y se piensa en practicar una miomectomía más tarde cuando el estado general estuviera repuesto y lo permitiera. Mientras tanto se ordenan exámenes de laboratorio y se trató médicamente con hielo, ergonovina, penicilina, estreptomicina, suero antigangrenoso, extracto hepático, calcio, vitamina C y taponamientos intrauterinos con sulfa. Con los taponamientos se comprobó la presencia de fragmentos del tumor dentro de la cavidad uterina esfacelados y necrosados. Estos disminuyeron la cantidad y la fetidez de los loquios pero el estado general continuó el mismo: postración, sensibilidad en el hipogastrio, violentos escalofríos, fiebre de $39^{\circ}$ y $40^{\circ}$.

El 18 de mayo aparecieron signos de flegmasia alta dolens en la pierna derecha, pero cedieron en pocos días con el tratamiento médico del caso. Se pensó en una septicemia por estreptococo hemolítico pero el examan de laboratorio dió resultado negativo. Los otros exámenes de laboratorio practicados fueron los siguientes:

Orina: ligeras huellas de albúmina; leucocitos -|-; hematies, -|-; cilindros granulosos, -|- -|-

Sangre: hematies: 3.060 .000 ; leucocitos: 7.200 ; hemoglobina: $69 \%$; valor globular: 1 ; neutrófilos: $80 \%$; linfocitos pequeños: $17 \%$; metamielocitos neutrófilos: $3 \%$; sedimentación globular: a la media hora, 125 m. m.; a la hora, $150 \mathrm{~m}$. m. Tiempo de coagulación: 8 minutos.

\section{Operación.}

Se efectuó un mes después del aborto o sea el 25 de mayo de 1949. Para esta fecha los fenómenos infecciosos generales habian disminuído muy poco y los fenómenos locales habían variado bastante. La altura del tumor bajó a 17 centímetros y además la consistencia se hizo blanda.

Laparotomía mediana infraumbilical; al abrir el peritoneo saliớ un chorro de pus fétido; cuidadosamente se exploró la región y se eficontró una masa blanda, ovoide de-superficie irregular despulida, del ta- 
maño antes indicado, fétida y con algunas adherencias. Al destruír éstas y al tratar de exteriorizar la masa se notó con gran sorpresa que estaba completamente aislada, sin pedículo de ninguna clase y alojada en una especie de cápsula de membranas de neoformación independiente de la gran cavidad peritioneal. Esta cápsula tenía una salida por abajo que la comunicaba con la vagina a través del canal cervical, que era lo único que restaba de aquel útero, lo cual se comprobó pasando una sonda de Nelatón. Se dejaron 10 gramos de sulfa en polvo en dicha cavidad y se colocó dren con salida a la pared. Sutura en dos planos seromúsculo-aponeurótico y cutáneo. Anestesia ciclo-éter. Duración: tres cuartos de hora. Cirujanos: Profesor r Mojica y C. R. Silva Mojica.

Post-operatorio: hielo, morfina, penicilina. Se traslada a la Sala de Infectadas. A pesar de las pésimas condiciones en que fue operada la paciente presentó una mejoría sorprendente en los dias siguientes. Pero al séptimo día apreció una fístula intestinal al extraer los drenes.

Con todo esto, la mejoría fue más acentuada cada día. Se trató con penicilina, extracto hepático y vitamina C. La fístula vino a cerrarse espontáneamente un mes después, es decir, a fines de junio, pero quedó una ulceración en el sitio de la laparotomía, que fue cerrando lentamente gracias a aplicaciones locales con polvo de sulfa y con sangre $y$ cerró por completo a principios de agosto.

La pieza operatoria fue enviada al Laboratorio de Anatomía Patológica de donde enviaron esta respuesta con fecha de mayo 31 de 1949:
"Tejido, órgano o region: utero.

Diagnóstico clínico: fibroma uterino con necrosis séptica.

Descripción macroscópica: una masa de tejido de color gris violáceo de forma aplanada, de mal olor, y superficie irregular que presenta estrias y anfractuosidades de color negro. Dimensiones: $13,5 \times 13 \times 3,5$ centimetros. La superficie de sección es de color gris rosado con una arquitectura que recuerda la del fibroma y es de consistencia blanda.

Diagnóstico microscópico: necrosis. Los cortes muestran tejidos que da la impresión de ser tejido muscular liso y tejido conjuntivo fibroso, en estado de desintegración. También se ven formas de estructura que parecen ser fondos de saco glandulares. No es posible dar más detalles histológicos. (Firmado) M. Sánchez Herrera, Jefe de la Sección".

El 17 de agosto practiqué T. V.: vulva y vagina normales: cuello duro, pequeño y cerrado; fondos de saco vaginales: nada especial. El cuello queda interrumpido casi a nivel de la cúpula vaginal; ningún cuerpo le hace continuación, por lo tanto se pone en claro la ausencia de la matriz. Estos datos nos recuerdan la impresión obtenida en los casos de histerectomia subtotal común $y$ corriente.

\section{Consideraciones generales.}

La presencia del fibroma uterino y sus caracteristicas, nos explican los fenómenos presentados por la paciente. El aumento del tamano de la matriz, en relación con la última regla, ya que los miomas también sufren hipertrofia e hiperplasia con el embarazo. 
La amenaza de aborto en el mes de enero, así como también la causa del aborto efectuado en el hospital más tarde el 25 de abril. Los fibromas ocasionan con frecuencia el aborto tanto más si son de gran tamaño. Entre los antecedentes ginecológicos de la paciente solamente hay uno que nos da indicio de la existencia del fibroma: ciclos regulares de $28 \times 4$ pero menstruaciones abundantes. No hay dato de verdadera menorragia por tratarse de un tumor intersticial, ya que los más hemorrágicos son los submucosos.

El tamaño mismo del mioma, su localización en la cara anterior de la matriz y su espesor hicieron difícil la apreciación de polos y partes fetales, como también de la cantidad de líquido amniótico.

Los dolores que mortificaban a la paciente en la región sub-umbilical al ingresar al Servicio, se debieron a un proceso de necrobiosis aséptica que venía desarrollando el mioma durante el embarazo.

Esta necrobiosis aséptica se transformó durante el puerperio en necrobiosis séptica como lo indican los fenómenos locales, crecimiento del tumor, mayor dolor, mayor dureza y posteriormente reblandecimiento y reducción; y los fenómenos generales, fiebre elevada, taquicardia, intenso ataque al estado general, sedimentación aceleradísima, anemia, hiperleucocitosis, etc.
La llegada de gérmenes virulentos al mioma, por vía vaginal posiblemente, favoreció al aparición del cuadro séptico.

Es probable que la aplicación poco prudente de ergóticos durante el puerperio, además de la virulencia de los gérmenes, haya coadyuvado a la producción de la necrobiosis séptica y en fin a ese tipo de amputación espontánea de la matriz, puesto que aquellos producen isquemia de los tejidos.

El interés de este caso reside en la evolución particular del proceso, en su rareza, ya que una amputación de la matriz por necrobiosis no la he encontrado descrita en las publicaciones obstétricas como tampoco he tenido noticia por parte de profesionales de larga práctica en la especialidad, de un hecho semejante a este; en el resultado final satisfactorio pese a las múltiples complicaciones que acaecieron; en la valiosa enseñanza deducida a la observación y cuidado de ese caso y en la confianza cimentada una vez más en nuestros principios tocológicos, en los métodos quirúrgicos y en el efecto potente de los modernos antibióticos.

\section{Bibliografía.}

Te Linde. Operative Ginecology.

De Lee, Greenhill. Principles and practices et. obstetrics. 8 th. ed.

Mojica Carlos J. Comunicación personal. Year Book. 1948. 